\title{
Contradictions within an activity of second language reading literacy
}

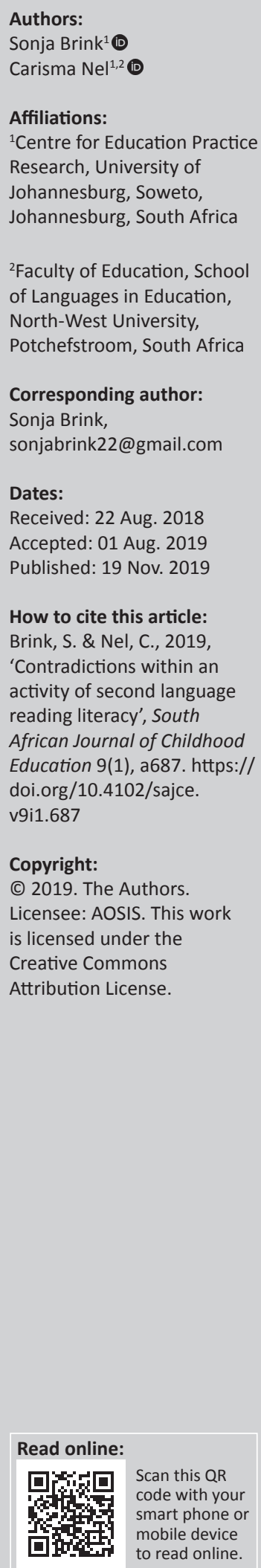

Background: In investigating the early reading literacy of a group of Setswana-speaking children who learnt to read in Afrikaans, cultural historical activity theory (CHAT) was chosen as a conceptual framework because of its proven utility value in helping researchers make sense of complex social systems.

Aim: The application of this heuristic not only proved valuable as organising principle but also unexpectedly revealed the situation with a clarity that brought about a richer understanding of the intricate dynamics underlying reading literacy in a second language.

Setting: The study was conducted at a small-town Afrikaans medium school.

Methods: In this mixed method inquiry, qualitative data was collected through interviews with parents and educators, classroom observations and document analysis. The quantitative data was obtained through the administering of an early reading literacy assessment.

Results: The overarching finding of this study was that the Setswana-speaking children developed early reading literacy skills at a rate and level commensurate with that of their Afrikaans-speaking peers. Where the application of $\mathrm{CHAT}$ as heuristic proved invaluable was in bringing to light a pattern revealing the agency which was exercised by parents and educators to support the children's reading literacy learning.

Conclusion: Despite various obstacles and tensions, parents and teachers exercise considerable agency in supporting the children's early reading literacy. Although the empirical aspects of the study are described, it is a conceptual gaze of the situation, employing CHAT as a lens, which is the focus of this article.

Keywords: early reading literacy; second language learning; cultural historical activity theory; CHAT; Setswana-speaking; Afrikaans.

\section{Introduction}

Early reading literacy is one of the most important aspects of a child's first years at school. Children need reading literacy to progress through life (OECD 2016). Although the country's language in education policy states that all children have the right to be educated in their home language, many children in South Africa learn to read in a second language - often English or Afrikaans. Teaching children to read in a second language constitutes complex education situations for educators and parents in South Africa.

English currently enjoys considerable status and is seen by many as a means to access the job market (Casale \& Posel 2015). Afrikaans has, over recent years, been perceived as less desirable in this respect (Greenfield 2010; Webb 2010). Indeed, Afrikaans as a language in education is currently a much contested issue. This contention shows in the current trend to change Afrikaans medium schools into either English or dual medium schools - as is clear from the statement made by a Member of the Executive Council, Panyaza Lesufi, who, in 2015, announced that 124 Afrikaans medium schools in the Gauteng province had been earmarked to be converted to dual medium schools (Lesufi 2015). When looking at the actual choices which parents make regarding their children's language of the classroom (LoC), ${ }^{1}$ it appears that there is a dichotomy between the views of policymakers and academics, and the perceptions of people at grassroots level.

Language is unquestionably one of the aspects of education delivery, together with other factors such as socio-economic status, parental education, home support, etc., which play a major role in the dynamics of a classroom. It is obvious that the teacher who speaks the LoC and who teaches 1.In this article, the term "language of the classroom" is used instead of the ubiquitous 'language of learning and teaching' as proposed by Brink (2016) 
children from that same language background has a much easier job than the one who has to negotiate the complex dynamics of a classroom full of children from language backgrounds other than the LoC. Unless all learners come from a homogeneous language background, schools can be viewed as a situation-in-flux with regard to their role as agents of literacy learning. Because learning to read in a second language is an entirely different science from learning to read in a first language, schools need strategies to ameliorate difficulties for learners who speak languages other than the LoC.

Furthermore, the social and political interplay between parents and the school and between the school and the local community affects children's literacy learning. Moreover, the school's situatedness within the larger education system of which it is a part (and from which it receives certain directives of how literacy learning should take place), is a determinant of how literacy instruction is delivered.

Opinions about the LoC, and particularly whether mother tongue education best serves children's education, abound in the literature. More recently, a number of researchers have averred that mother tongue education, at least early on in a child's schooling career, is best to advance learners' chances of later success in school (Alidou et al. 2006; Brock-Utne 2007; Heugh 2011; Ngcobo 2013; Nel \& Theron 2008). This is because it enhances the development of cognitive and communication skills and gives children a firmer grasp of language rules and grammar. At grassroots level, however, parents choose the school which they want their children to attend and children often attend schools where a language other than their home language is used as the LoC.

Rather than viewing agency as a trait or capability that people possess, this article invites the readers to see it as an emergent phenomenon - as actors who act by means of their environment (Priestley, Biesta \& Robinson 2015). It proposes that agency comes about as a result of the interplay between efforts by the parents to secure a quality education for their children, despite a lack of fiscal and knowledge resources, and other contextual and structural factors such as the LoC and the directives of the curriculum. Priestley et al. (2015) offer an ecological view of agency: the unique interface of aspects that influence children's education. Researchers in education are often confronted by confounding data gained from within complex social dynamics where a host of different forces might hold sway. Fitting such an ecological view of agency as proposed by Priestley et al. (2015) into the application of a conceptual organising principle such as cultural historical activity theory (CHAT) could help the researchers to make sense of the research situation and therefore bring the benefits of new understanding to the knowledge community. This article offers the readers such a view. Empirical aspects of the study, such as the main findings - that the Setswana-speaking children learnt to read at a rate commensurate with that of their Afrikaans-speaking peers - are mentioned in order to provide a context to the activity system. Although the Setswana-speaking children and their reading literacy learning in Afrikaans are the subject of the activity, the focus of the situation, the focus of this article is different: it deals with the application of a heuristic gaze - that of the situation as an activity - and not with the details of the children's reading literacy learning. Although the children and their reading literacy learning stand central to the situation in the research, in the activity system the focus is a little different; it is the children's forward momentum towards early reading literacy that provides the impetus for the actions and interactions of the various actors in the activity.

\section{Cultural historical activity theory as a lens}

Cultural historical activity theory was chosen as a conceptual framework because of its proven utility value in helping researchers make sense of complex social systems and the dynamics which impact them when there is little to be gained from the literature (Van der Vyver 2012). The application of this heuristic not only proved valuable as an organising principle in lieu of information on aspects of linguistics, but also unexpectedly revealed the situation with a clarity that brought about a richer understanding of the intricate dynamics underlying reading literacy in a second language.

The CHAT was developed by Engeström (1987, 1991, 1999, 2001) from Vygotskian cultural historical theory to elucidate the role of tensions and contradictions within a complex activity system (Engeström 1999:384) (see Figure 1). Vygotsky (1978) had proposed that human activity is mediated by tools and signs which are acted upon by various semiotic indicators, such as language. The notion of activity should

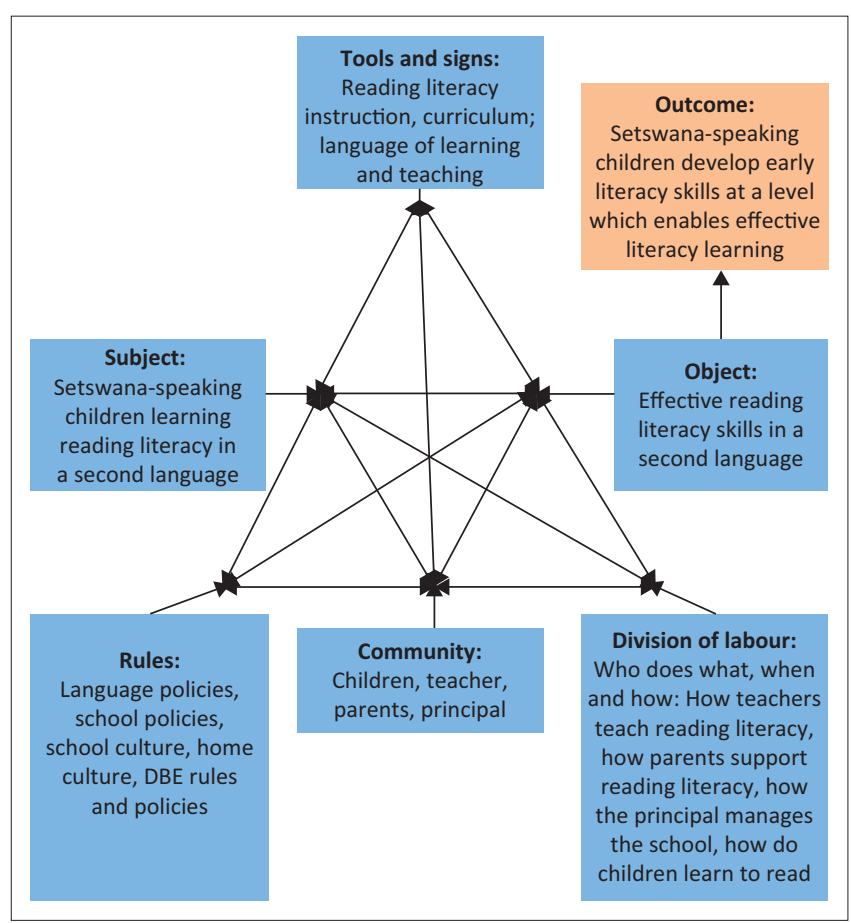

Source: Engeström, Y., 1987, Learning by expanding, Orienta-Konsultit Oy, Helsinki. FIGURE 1: Interrelatedness of elements of second-generation activity theory. $\mathrm{DBE}$, Department of Basic Education. 
always be taken to have human collectives rather than individuals as its focus - it is always about the combined actions and relationships between individuals, groups and the environment. A central tenet of Engeström's theory is its focus on the interrelatedness between all aspects of the activity or system (Beatty \& Feldman 2009), and specifically how all these factors impact the central movement - for in an activity the object is always in motion from a certain state to another, envisaged as a state of being. Activity refers to the ongoing engagement of the object of the activity - here, the Setswana-speaking children - in an action towards a specific objective - in this case, learning to read in Afrikaans.

Engeström distinguishes between different levels of contradictions within a system. The 'primary contradiction' is always present and forms the basis for the other levels of contradiction. Using the discourse of a capitalist system, Foot (2014) describes the contradiction at this level as 'tensions in a capitalist system that stem from the opposition between use value and exchange value'. We propose that, from an educational perspective, in this situation the use value be represented by 'learning reading literacy' as a commodity to access further education and that the exchange value represents the exchange value in the system, and that the tensions between the two - between becoming reading literate and having to do so in a second language - constitute the primary contradiction, the one that is omnipresent and that underlies all other contradictions in the activity.

Secondary contradictions come about as a result of conflict between two nodes of the activity system (Foot 2014) - for example, between roles and the division of labour. Having outlined the primary contradiction and keeping in mind that it remains the same and is not changed by the temporary or permanent resolution of other contradictions which might exist in the system, it is this second level of contradictions that is the focus of interest. In the section below we will describe the nodes of this activity system and conceptually position the components within the situation at these nodes.

Within the heuristic of the activity system, the acting/ engaging subject, which is the person or group whose actions the researchers are seeking to understand, makes use of tools such as language, aspects of reading instruction and curriculum directives about early reading to move towards the object of the activity - Setswana-speaking children who are learning to read in Afrikaans. In doing so, certain outcomes are envisaged. In this case, the envisaged outcome is that the Setswana-speaking children would develop the necessary early reading literacy skills to enable them to read.

This action towards an outcome does not however happen in a vacuum but is impacted by various role players - the community - who are stakeholders in the activity. In this study, the parents, the Grade 1 teacher, the school and the larger education system might be seen as stakeholders in the children's literacy learning. How tasks, such as teaching or homework support, are allocated to specific members of the community constitutes the division of labour within the activity.
Division of labour also refers to how the community is organised around structures of power and status. In this study, for example, parents who cannot speak Afrikaans are not in the same position of power when it comes to being able to render homework support to their children than Afrikaans-speaking parents at the school. Closely linked to the division of labour and distribution of power are the rules according to which the system functions and to which all activity within the dynamic is subject. Rules include official regulations, such as the directives of the education department, school regulations and classroom rules. An example of this is how a teacher differentiates lessons so that children from language backgrounds other than the LoC are not disadvantaged and, thus, fall behind. They also include the conventions and beliefs which are valued by the community which might not be documented but which still form part of the local consensus. For example, for the parents of the Setswanaspeaking children at the school, perceived education quality weighs heavier than language affiliations when it comes to what they value in a school. All of these rules have impact upon the actions of the subjects, to what effect it can utilise the tools at its disposal and to what extent it will adhere to the directives of the division of labour within the community.

The tools are essentially semiotic instruments of mediation, which convey the norms and signs of the culture-specifically as these manifest in language. Tools can be physical, such as the classroom or cognitive, for example, teaching strategies. Examples of symbolic tools and signs which are used by educators are language and conversation in the classroom, visual aids and, most importantly, the national curriculum.

It is important to note that no activity system functions in isolation as a unit of itself but that it also forms part of other, interconnected or wider systemic and historical contextual systems (Beatty \& Feldman 2009:18). In order to render the situation as completely as possible, it is therefore necessary, when speaking of activity systems, to present what Geertz (1973:311) refers to as a 'thick description'. By application of an analytical tool, this article aims to render such a description of one system and its tensions. The setting and role players together with the empirical details of the research, as well as the tensions which were brought about by the children's reading literacy learning in Afrikaans, are described. Secondly, this article highlights how these tensions brought about, for parents and educators, the impetus for searching for ways to overcome the obstacles that stand in the way of the children's reading literacy learning. It concludes with how the application of CHAT can be employed to make sense of a complex situation during research and how it can enhance a theoretical view of an empirically thick description (Geertz 1973).

\section{Contextualisation}

The school in the study is the only Afrikaans medium primary school in the area where about $40 \%$ of the learners are Setswana-speaking students. Eight years ago, the school's demography changed drastically when another Setswana 
medium school in the area closed down and its entire population was transferred, by default, to the Afrikaans medium school. As the school offers Grades 1-7, all of the learners who had been transferred then had already left the school at the time when this research took place. Setswanaspeaking parents were, therefore, free to send their children to any school of their choice. In spite of this, parents selected this school over others because of the following: the children might learn to read in Setswana, the school location might be closer to where they live or it might be a no-fee school.

Many of the Setswana-speaking children at the school come from resource-poor backgrounds. Several aspects of their home environment make it difficult for these parents to support their children's reading literacy. Some parents cannot speak Afrikaans, or are illiterate, or work long hours and they cannot spend time helping the children with homework. A few of the children come from more affluent, middle-class households. These parents seem to select this school over several other public, and also private, schools in nearby Johannesburg.

\section{Methodology}

Although the focus of this article was not on the empirical aspects of the study, the findings form the basis from which the secondary level of contradictions spring. For that reason, and also to afford the readers a context, we provide an outline of the data collection methods and analysis that was employed in order to arrive at the findings of the study. Although the children and their reading literacy learning stood central to the study, in the activity system the focus is a little different; it is the children's forward momentum towards early reading literacy that provides the impetus for the actions and interactions of the various actors.

Both quantitative and qualitative data were utilised in this study. Several qualitative data collecting strategies were employed, such as interviews, observations and document analysis, from which a large body of data ensued. Quantitative data were obtained through the administration of an early reading literacy assessment and formed an axial part of the data as it indicated the children's progress in early reading literacy.

\section{Study population and sampling strategy}

Sampling for the empirical component of the study was performed by purposeful selection of the intact group that constitutes the case. The following key participants were identified and included. Apart from the group of 10 Setswanaspeaking children whose reading literacy progress was assessed, their parents, ${ }^{2}$ their school principal and the Grade 1 teacher were chosen as subjects for the research because they would be able to give information on the children's socio-economic backgrounds, their early reading literacy experiences and to what extent the children had previously encountered print. Parents would also be able to tell why they chose the school over others in the area. Furthermore, it was important to find out what parents' education and literacy levels were, and also to establish parents' proficiency in Afrikaans, how they perceived themselves as agents of support of reading literacy and their attitudes to the challenges which the children as second language learners would unavoidably face in their early school careers.

\section{Data collection methods Questionnaire}

A pen-and-paper questionnaire containing fixed and openended questions was used to determine the teacher's knowledge and perspectives on aspects of reading literacy, such as phonemic awareness and reading literacy instruction. Results from this data source showed tensions between the teacher's lack of knowledge about aspects of early reading literacy and his or her engagement in the activity of teaching it.

\section{Interviews}

Semi-structured, face-to-face interviews were conducted with the school principal, the preschool teacher, the Grade 1 teacher and the head of department (HOD) of the Foundation Phase at the school. These aimed to gather data about their orientation to the reading literacy of Setswana-speaking children at the school. Parents too were interviewed to find out more about their attitudes towards the children's reading literacy, the children's home contexts and the role it played in the children's reading literacy.

\section{Observations}

In this study, the first author was a participant observer who used ethnographic methods such as keeping field notes in a diary and made video recordings of the Grade 1 teacher's classroom practice. This afforded the researchers an opportunity to explore the natural dynamics and actions of a group of people in their natural situation, and therefore render a comprehensive picture of participants' views within their ever-changing natural situation.

\section{Data analysis}

The analysis of the qualitative data was performed through content analysis by following processes of coding and categorising. The final step in the data analysis process was the examination of categories and how they relate to one another and to specific themes identified in the research. These themes were then described and used as a wellspring from which the authors discuss the issues pertaining to the research, push forward arguments and draw conclusions about the outcomes of the research.

The themes were conceptually positioned to denote tension between the different nodes of the activity system in order for the researchers to make better sense of such a 
complex situation. The use of discourse analysis was not explicitly intended in the planning of this research. Even so, some discourse markers came to the surface when a strong pattern of tensions within the situation was configured through the analysis of the data. The use of content analysis ensured that the analysis process remained true to the actual lived experiences, words and actions of the participants, from which the codes were closely derived.

\section{Ethical considerations}

Ethical clearance was obtained from the Ethics Committee of the North-West University (NWU), Potchefstroom (clearance number: NWU-00071-13-A2).

\section{Results and discussion}

The overarching finding of this study was that the Setswanaspeaking children developed early literacy skills at a rate and level commensurate with that of their Afrikaans-speaking peers. How they managed to do so is represented by the findings which were derived from the qualitative component of the study. These themes are presented and discussed in terms of the tenets of CHAT.

Firstly, at this school, it is clear that parents make a conscious decision to enrol their children even though (and in some cases, because) the LoC is Afrikaans. The parents choose this school for various reasons, mainly because it is perceived to offer a better-quality education than other schools in the area. In order to prepare children for their school career at an Afrikaans school, parents take the ameliorative precaution of enrolling their children at the Afrikaans preschool nearby. Supporting their children's early literacy learning is a challenge for the parents, not least because of a scarcity of fiscal resources, but they devise various strategies in order to optimise their children's learning. Some parents enlist the help of Afrikaans-speaking members of their home communities to assist, others make an effort to increase their own knowledge of the language and yet some others simply listen attentively to encourage the children to practise their Afrikaans reading despite not understanding what their children are reading to them.

The school is found to be a functional and child-centred place of learning, even though teachers are expected to adhere stringently to the national curriculum and the directives of the Department of Basic Education. This causes considerable tension within the activity system. For example, the HOD's expectation of the Grade 1 teacher to stringently adhere to the curriculum in terms of the children's production of written work stands in stark contrast to the teacher's classroom practice which included a number of phonics activities. The teacher lacked knowledge of phonemic awareness and other early literacy skills and, therefore, aspects of her literacy teaching actually work contrary to optimal literacy learning. Reading literacy practice focuses on phonics and word recognition, with little purposeful focus on phonemic awareness as such. Despite these deleterious factors, the Setswana-speaking children seem to learn to read easily - probably because of the transparency of the Afrikaans orthography (Brink 2016).

The utility value of CHAT as a heuristic shows up prominently when the themes, which were derived from data analysis, are mapped onto an activity system. From the discussion of this conceptual 'fit', a strong pattern emerges. Parents and educators face significant challenges in supporting the children's reading literacy - both within the local situation and from the larger, systemic context. Despite these challenges and the tensions which they bring about, they take full power in innovating ways and using resources that would enhance the children's learning abilities. Because of their stalwart commitment to this end, the children make progress in their early reading literacy learning. A few examples of the challenges, tensions and also of the agency exerted by the role players in the situation will be highlighted next.

There are tensions between the parents' choice of a school for the educational benefits, which parents believe the school affords their children, and the consequences of that choice that is, not being able to help their children with homework, nor being able to access information from school newsletters and parent meetings as these are written and conducted in Afrikaans.

The school's local situation also stands in sharp relief to its place within the larger education context. The strict protocols which the DBE prescribes, for example, with regard to have children produce written work as evidence of learning, and the administrative workload brought about by assessing learners and recording the results of these assessments go against the grain of the teacher who sees these as timeconsuming and often superfluous to the achievement of more important outcomes, such as learning to read.

At an intra-school level, the systemic directives from the DBE cause tension between the different stakeholders at the school. The school principal perceives these directives, especially in terms of the time commitment which they demand, as putting undue pressure on educators, which has a negative impact on children's learning. The HOD, however, does not share the views of the school principal and the Grade 1 teacher on the value of strictly adhering to the curriculum and other departmental schedules and believes that these are essential for successful teaching and the effective functioning of the school.

These examples show that there is considerable tension within the activity. Looking at the situation through the heuristic of CHAT makes it clear that a tension exists between all the 'nodes' of the system. For example, there is tension between the school's language (a tool) and its community (the Setswanaspeaking children and their parents) engaged in the activity.

In the activity system, the role players aim to address the tensions which manifest in a way that would best serve the children's learning. By taking command of aspects, such as 
their choice of a school, parents stand by no means powerless in the situation. They decide on this school as one which would, despite costing them more in time and money than other schools in the area, would optimise the children's chances of getting a quality education. Parents believe that this school gives children the best chance of learning to read, and reading to learn, to succeed at school and later on in life. Similarly, the educators take the bull by the horns and constantly work to find better and more innovative ways to support the education and well-being of their learners. In tandem with the tensions within the children's early reading literacy context, agency comes to the fore as a strong pattern in the activity system.

Tensions are brought about within the context of the school and its community by factors from within the locality as well as the society. To address these tensions, the role players in support of the children's reading literacy - parents and teachers - opted to exert considerable agency in finding ways to overcome the challenges which present in the situation.

Contradictions are frequently brought about by the complex interplay between sometimes opposing aspects of education provisioning, such as the reality of learners who are learning in a second language and the demand this puts on the teacher's time, and the limited time provision by the curriculum for early literacy learning activities. In addition, socio-linguistic factors, such as language identities - both of the learners and the school - and considerable tension could result, putting strain on the situation within which reading literacy learning takes place. If not properly managed these tensions could be to the detriment of children who are often already challenged by a shortage of fiscal and knowledge resources at home. Furthermore, the school as a matrix within which the children are educated could easily be warped into a less than ideal learning situation by larger influences such as curricular and departmental directives and how these are enforced locally.

Referring to those who influence the children's learning in this situation - the children's parents and teachers - we want to propose that tensions could be the very thing that brings about a sense of agency for role players to direct their actions within the system in such a way that they benefit the children and their developing reading literacy. Without a sense of agency on the part of educators - of a willingness to do what needs to be done to support children's early reading literacy learning - it might prove near-impossible for children to make sufficient progress in their literacy learning to get to the end of learning to read and to start reading to learn in Grade 4. Likewise, were it not for parents' willingness to work at finding ways to support their children's reading skills, by devising strategies which aim to optimise the children's chances of succeeding at the school, the best efforts of the teachers might very well have come to nothing.

There are clearly enough forces working contrary to the effective acquisition of early reading literacy skills in South Africa - as is evident in our abysmal scores on international reading assessments (Spaull 2013). It is our opinion that instead of trying harder to eradicate the obvious dichotomies causing tension within the situation, parents and educators should allow the focus to be drawn acutely to challenges in the way of early reading literacy learning and to harness these tensions to provide the impetus to act towards overcoming obstacles.

The shortage of data on the effects of orthographic depth on reading in Africa makes it challenging to find existing ideas from which a conceptual framework for studying this aspect of reading literacy can be drawn. The application of a conceptual lens, such as CHAT, could help maintain a certain focus of activity as a dynamic, and not as a static, situation, especially given the complex social dynamic underlying language acquisition and reading literacy learning. In this article, the authors propose the use of CHAT as proposed by Engeström (2001) to anchor, conceptually, a view of learning to read in South Africa as fraught with tensions and the ever-changing dynamics. The application of a heuristic is, of course, merely a tool - one which affords one a different view - depending on the angle at which it is applied to the situation under investigation. Together with Henning and Gravett (2011), this article argues that it might help researchers in South Africa to gain a better understanding of the practice of supporting learning to read in a second language when language is viewed as a semiotic tool - one which, in the hands of educators and parents acting with agency, could serve to support the crucial stage of early literacy learning for children in South Africa.

The remainder of this article now maps the tensions which emerged within the situation onto a conceptual activity system construed according to CHAT and shows how parents and teachers devised compensatory stratagems to support the children's early reading literacy.

\section{Stratagems to support early reading literacy}

By using CHAT to explore the different tensions which manifested in the context, each of the findings is conceptually positioned between two 'nodes' of the activity system. Next, the tensions which came to the fore from within that position are then discussed and, in each instance, it will be shown how the parents and teachers - the people who make up the community within this activity system, through their agency, exercised their political will by wielding the tool of, for example, a shallow orthography to help children to effectively act towards the object of literacy learning and, therefore, to help them reach the objective of attaining reading literacy in Afrikaans.

Various contradictions within this activity system are discussed, each time, in conjunction with one of the findings of the study. What follows is not meant to be an allencompassing detail of all the possible tensions within the dynamic of the activity system but, instead it deals only with 
the most prominent ones. A representative sample of raw data is presented in each case.

\section{Contradictions between tools and signs and community: This is the school of choice for Setswana-speaking parents}

As stated by a parent:

'A lot of the problem is ... I can't help her in Afrikaans. Even the school newsletter is in Afrikaans and I don't know it, so I run to my neighbour for help. She is Afrikaans and she helps me to understand it [the newsletter].' (Parent 4, female, 32 years old, Grade 12, works as a petrol attendant)

Parents, members of the community, exert considerable agency in choosing this school for their children. They do so because they believe that their children will benefit from some tools which they believe can be found within this setting. These tools include teacher knowledge, effective management structures, disciplinary procedures, a caring environment and instructional practices. Parents see the educators here as capable of optimising the use of these tools in order to ensure their children's academic progress and well-being. Whatever the utilitarian value that parents might ascribe to these tools and their application at the school, they are also aware of their own limitations in supporting children's schoolwork when they cannot speak Afrikaans, or cannot speak it well. Herein lies tension and from this perspective the LoC becomes a rule which lessens, considerably, at least for some of the parents, their power to intervene or assist in their children's reading literacy.

\section{Contradictions between tools and signs and division of labour: The school is functional and child-centred}

As stated by a teacher:

'I want to make sure the children learn to read ... [but] one of the biggest challenges is the curriculum ... I feel ... with the English [second language] ... some days I feel I am not exactly where I should be with it. I don't always understand how the children make it their own ... I don't know how they do it, especially the Setswana speaking children ... I feel that we should first get on top of the Afrikaans sounds in the first and second term and then only start with the English.' (Teacher, Grade 1, female, 47 years old)

According to their evaluation, the DBE, which forms part of the community within this system, deems the school a functional place of education. Parents, who are also part of the community, perceive the school in the same way. The school could, therefore, be described as an institution of education where the division of labour is effective. The school functions well because everyone - the principal, teachers, members of the school governing body and the supporting staff seems to be aware of what should be done, by whom, at which time and according to what standards. The well-being of the learners is the focus of much of the stakeholders' actions. However, tensions manifest between the strictures of the DBE, regarding adherence to administrative procedures as tool - and the teacher's perception of these as limiting his or her ability, within the division of labour, to help the children to learn to read.

\section{Contradictions between tools and signs and the object of the activity: Teachers lack knowledge of early reading literacy skills}

Statement by a teacher:
'A teacher's response to a question: Describe/give an example of phoneme blending:
Candle + wax $=$ candlewax. It is when you put two words together.' (Teacher, Grade 1, female, 47 years)

Teacher knowledge constitutes an essential tool in this activity system. The teacher lacks knowledge of early reading literacy skills, such as phonemic awareness, and how these are supposed to be taught. This brings about tension between tool and the object of reading literacy. Despite this the Setswana-speaking children learn to read at essentially the same rate as their Afrikaans-speaking peers. Here the authors argue that children's success in early reading literacy was furthered by the shallow orthography of Afrikaans - another tool in the system.

\section{Contradictions between the tools and signs and rules: The national curriculum is the teachers' strict guide}

As stated:

When the [foundation phase] teachers ask me what they should be doing about this or that [aspect of their teaching], I tell them to go read the CAPS [cultural historical activity theory]. Everything they need to know is in there. Everything. (Head of Foundation Phase Department, female, Teacher, Grade 2, female, 57 years old)

The national curriculum can be seen as a tool which is used for gaining the object of the action in the activity of early reading literacy. Here, however, the teacher lacks autonomy in applying the tool to best fit the unique situation in his or her classroom. Strict rules, in the form of a set of instructions issued by the HOD, for which she draws upon from the prescriptions of the DBE govern how the tool is used. The HOD, who is also a part of the community, stringently enforces these rules and in doing so, escalates the tensions within the situation. The teacher, acting according to what he or she believes is the best practice in reading literacy teaching, by surreptitiously and under considerable criticism, interprets the curriculum - a tool in the activity - in a way that gives him or her the opportunity to tailor the classroom practice (another tool) to serve the children's reading literacy needs in the way he or she deems best.

\section{Contradictions between community and rules: The school adheres strictly to the DBE's rules, despite scepticism}

Statement by teacher:

'We should teach one sound at a time and inculcate before we continue. The department jumps around between the different sounds and so nothing gets properly inculcated.' (Teacher, Grade 1, female, 47 years old) 
Part of the community in this activity system is the school and the educators. It is clear that teachers feel hindered by the stringent directives of the national curriculum and the DBE in their task of optimally developing children's early reading literacy. Teachers feel that the time strictures around literacy activities in the classroom are preventing them from effectively focusing their teaching in ways that would provide more learning opportunities for children to practise, for example, awareness, phonics and reading for meaning. The teacher and the school principal perceive many of these rules as redundant prescriptions policed by departmental officials who lack the capability to do so.

\section{Contradictions between rules and the object of the activity: Written work is seen as evidence of learning}

As stated by a teacher:

'Parents expect children to do work on paper [and] that makes it difficult because the parents want to see results. And the only way to show them results or outcomes is to show them - I have assessment books - then you can show them, look, this is what your child has done this term. If you do everything orally or with clay then they [the parents] say how do they know you assessed correctly.' (Teacher, Grade R, female, 39 years old)

The need for children to produce written work to evidence their learning presents in several of the data sets. Spelling correctly is another rule which pervades in this activity system. These classroom activities take up a significant portion of literacy sessions. Tensions come to the fore during a 'monitor and support' visit by representatives of the Gauteng Department of Education to the school. Because the teacher had not followed the rules of having the children complete the prescheduled work in their workbooks, and had instead let the children practise their reading skills, the children had failed to complete the required amount of written work. This causes significant tension for the teacher who had acted according to his or her own view of what it is, within the division of labour, that he or she should be doing to advance the children's reading literacy even if it goes against established rules. Here, tensions arise from the negative consequences which the teacher has to face as a result of having acted.

\section{Contradictions between rules and division of labour: Supporting learning in a second language is challenging}

Stated by teachers:

'The earlier the children come to preschool the better. If they get here at least in Grade RR then by the time they get to Grade R they understand Afrikaans.' (Teacher, Grade R, female, 39 years old)

'Because the Tswana moms don't always know what is expected of the children for homework the children's homework is often not done. So I allow a little time in the morning for them to do homework.' (Teacher, Grade 1, female, 47 years old)

The fact that Afrikaans is the LoC at this school, is an explicit rule within the system. The school's language policy bears testimony to that. There is little evidence that other languages are provided for outside of what is required by the curriculum. This imposes certain restrictions upon the actors performing their duties according to the division of labour in the system. Parents whose support of their children's education includes, especially at Grade 1 level, helping children with homework can often not do so effectively because they do not understand Afrikaans. Parents also find it difficult to access information which is disseminated through the tool of the school newsletter, because the newsletter is printed in Afrikaans.

Looking at the role of the teacher within the division of labour, and rules in the form of the pressures exerted by the directives of the curriculum in terms of time constraints on the teaching and learning of the first language, it is clear to see why teachers say that they find it difficult to support the reading literacy learning of children from different language backgrounds. Had the teacher not exercised agency with some of these rules, for example, by assisting Setswanaspeaking children with their homework before school starts in the morning or after school in the afternoon, the children's progress towards the object of developing early reading literacy might not have been quite so pronounced.

\section{Contradictions between community and the object of the activity: Setswana-speaking children's home environments do not support early reading literacy in Afrikaans}

As statement by a parent and teacher:

'Unfortunately I cannot help him with homework. Because I cannot read and write.' (Parent 3, grandmother of child, 64 years old, unemployed)

'The parents [of the Setswana speaking children] work all day. Or they cannot read and write. Or they don't understand Afrikaans. So it is difficult for them to help with homework. I am at school from just after six in the morning. Then the children, also children from the other grades, come to me to help them with homework.' (Teacher, Grade 1, female, 47 years old)

Parents, as prominent members of the community of the activity system, are well aware that the home environment presents little support for learning to read and that it, therefore, does not directly enhance their chances of reaching that objective. Parents address this challenge by ensuring that their children are exposed to Afrikaans, at the Afrikaans medium preschool, despite the tensions brought about by this system.

\section{Contradictions between community and division of labour: Setswana-speaking parents send children to the Afrikaans preschool}

Statement by a parent:

'We send them to Dina [the preschool teacher] so that they can learn the Afrikaans there and be ready for the school.' (Parent 2, female, 28 years old, unemployed)

Parents choose this school for their children's education. To ensure that the children reap the benefit from attending the school, most of the Setswana-speaking parents enrol their 
children at the Afrikaans preschool which is attached to the school. Parents see this as a way to make up for the lack of resources and support for learning to read in Afrikaans within the children's home context. Seven of the 10 children in the study had attended this preschool. Looking at the children's progress, it could be inferred that this approach of the parents works. It does, however, bring about some tensions in that the parents relinquish some of their power, within the division of labour, in order to prepare their children for school. Contradictory as it might seem, instead of the parents escaping their duties here, this might very well be where they exercise their will the strongest.

\section{Contradictions between division of labour and the object of the activity: Literacy practice is limited to phonics and word recognition with no purposeful focus on phonemic awareness}

Statement by a teacher;

'Sometimes I feel overwhelmed. There is just not enough time in the curriculum to properly inculcate the sounds ... and I am accountable to every child in my care. I can't just leave them when they struggle.' (Teacher, Grade 1, female, 47 years old)

The community working according to the division of labour within an activity system plays a significant role in either sustaining or hindering the impetus of the action of the subject towards attaining the object. In this situation, the teacher stands central, within the division of labour, to the children's early reading literacy learning. The labour involves teaching aspects of literacy such as phonics, word recognition and writing components which might not be as effective as explicit instruction in phonemic awareness to help the children, especially those who are struggling, to learn to read. Herein lies the tensions; the teacher does not have the knowledge tools to adjust his or her reading literacy instruction, nor does he or she have the curriculum tool, which he or she is expected to adhere to, by the rules, optimally serve the outcome of reading literacy for these children. We propose that a shallow orthography as a tool together with the agency exercised by a teacher in his or her teaching impacts positively the children's progress in early reading in their first year at school.

\section{Conclusion and implications for initial teacher education}

Having employed CHAT as a lens to look at Setswanaspeaking children who learn to read in Afrikaans, we draw a number of conclusions. Firstly, despite the obvious contradictions inherent in choosing, for whatever reason, a school where the language medium is not that of the child's home language, parents seem adamant that their children attend this school and they are willing to exercise their agency and exert considerable energy in devising strategies to overcome the challenges to early literacy learning brought about by their choice of the school. Notably, in this situation, there is no significant cooperation between educators and parents. Many conflicting views on early reading literacy learning were observed among the members of the community in this activity. There are also few indicators of structured collaboration between the school and parents to bridge the language divide for second language learners. Indeed, there is little evidence of dialogue about the challenges which each group faces in supporting the children's early literacy. In spite of this, it seems that the organically conceived strategies employed by parents and the separate and more formal professional strategies employed by the school are effectively support the literacy learning of the Setswana-speaking children so that they master early reading literacy skills at a rate which is on par with their Afrikaans-speaking peers.

The situation in this study confirms, once more, that a unitary view of community (Skogen \& Krange 2003), which ignores the intricate and often undocumented social stratification and power structures, is a myth and that a lack of fiscal, language and knowledge resources impacts significantly parents' and educators' ability to support children's literacy learning. This is where the application of a conceptual lens, such as CHAT, could bring clarity to researchers of the various interfaces, such as social stratification, and how these influence the division of labour.

Looking at the school and educators as agents of basic early literacy, there seems to be significant disequilibrium between the directives, or rules - such as curriculum requirements - of the larger education system of which the school is a part and what educators deem important in literacy instruction. This causes tension within the education setting and affects the way that early literacy instruction is provided. The Grade 1 teacher diverts from these directives and clandestinely follows his or her own set of rules about how early reading should be taught. This diversion from scripted rules has a local effect. For example, because the teacher spends more time than what is prescribed for oral language development, he or she gets into trouble with the school management team for not having the children produce enough written work. Ambiguities such as these serve to confound the scene for researchers who struggle to find patterns and coherence in the data. With the help of CHAT, however, researchers are able to retain a clearer view of the different and often opposing dynamics at play within the system.

Another conclusion that we have come to is the assumptions of academics and policymakers about the desirability of having Afrikaans as a language medium of education based on political, historical and sociocultural perceptions when statistics and local perceptions clearly indicate the contrary. We would argue for a realistic and practicable approach to literacy learning and for a shift in focus from the ideological to the pragmatics of linguistics, which includes a closer scrutiny of how aspects of the intrinsic structure of a language, such as its orthography, influence the ease with which learners become literate. More research is needed before another generation of children fail to learn to read at the level required for academic learning because of a misguided and politicised view of a language that has much to offer in supporting early literacy. Although this study was 
conducted on a small group of children at a specific locale, and although it does not extrapolate to larger activity systems, we would urge for more extensive research on the subject, as it could mean the difference between academic success and failure.

We would like to reiterate that conducting research on early reading literacy, given the vast array of factors that impact any situation at a local level - for example, resource poverty, a lack of knowledge regarding early literacy, second language learning, local power hierarchies, to name but a few - is a daunting task. However, if the situation is viewed as an activity that takes place at a specific historical moment, at a specific locale within a certain social, political and economic milieu, then what seems like discord and chaos could come to be seen as the impetus for a perpetual germination of new ideas by participants on how to navigate the often challenging terrain of supporting children's literacy learning to greater effect. Indeed, should researchers adjust the focus to include the entire system of the activity as the unit of analysis, it might serve to bring the seemingly opposing and discordant aspects of the research situation into an easy-to-understand picture - one from which important new insights on how to ameliorate the current crisis of poor literacy learning might come to the fore.

Finally, the analysis of the activity system presented in this article has significant implications for universities and the current discourse about teacher and teaching quality, and the effectiveness in improving educational outcomes, specifically the reading literacy of learners, and the criticism levelled at teacher preparation programmes (Taylor \& Mayet 2015). The fact that teachers in South Africa are encountering and will increasingly encounter a linguistically and culturally diverse range of learners requires that every teacher has sufficient breadth and depth of knowledge and a range of skills to be able to meet the unique needs of all learners, regardless of the language in which they need to learn to read. The International Reading Association (2003) states that:

Only if teachers are well prepared to implement research-based practices and have the professional knowledge and skill to alter those practices when they are not appropriate for particular children will every child learn to read. (p. 2)

There is growing consensus that much of what teachers need to learn must be learnt in and from practice rather than in preparing for practice (Hammerness et al. 2005). Zeichner (2010) argues for the creation of a 'hybrid space' in initial teacher education programmes that brings together schooland university-based teacher education and practitioner and academic knowledge in new ways to enhance the learning of prospective teachers. The work-integrated learning component of initial teacher education programmes has the potential to better prepare preservice teachers for the reality of the schooling environment, such as the tensions outlined within the activity system investigated in the research study presented in this article. Preservice teachers need more practice-based opportunities, related to their daily tasks of helping South African children learn to read, instead of being left on their own to work out the daily business of practice teaching by themselves with little guidance and support from all role players that affect the division of labour within specific activity systems.

\section{Acknowledgements}

The authors would like to thank the anonymous reviewers for their valuable input.

\section{Competing interests}

The authors have declared that no competing interests exist.

\section{Authors' contributions}

This article originates from the $\mathrm{PhD}$ study of the first author (S.B.). C.N. was the supervisor of the study.

\section{Funding information}

The author was the recipient of an NWU doctoral bursary during her studies.

\section{Data availability statement}

Data sharing is not applicable to this article as no new data were created or analysed in this study.

\section{Disclaimer}

The views and opinions expressed in this article are those of the authors and do not necessarily reflect the official policy or position of any affiliated agency of the authors.

\section{References}

Alidou, H., Boly, A., Brock-Utne, B., Diallo, Y.S., Heugh, K. \& Wolff, E., 2006, Optimizing learning and education in Africa: The language factor, ADEA, Paris.

Beatty, I.D. \& Feldman, A., 2009, April, 'Illuminating teacher change and professional development with CHAT', in Proceedings of the NARST Annual Meeting, 17-21 April, 2009, Garden Grove, CA, pp. 17-19.

Brink, S., 2016, 'The phonemic awareness development of Setswana speaking children at an Afrikaans medium small-town school', Doctoral dissertation, North-West University (South Africa), Potchefstroom Campus.

Brock-Utne, B., 2007, 'Learning through a familiar language versus learning through a foreign language: A look into some secondary school classrooms in Tanzania', International Journal of Educational Development 27(5), 487-498. https://doi. org/10.1016/j.ijedudev.2006.10.004

Casale, D. \& Posel, D., 2011, 'English language proficiency and earnings in a developing country: The case of South Africa', The Journal of Socio-Economics 40, 385-393.

Engeström, Y., 1987, Learning by expanding, Orienta-Konsultit Oy, Helsinki.

Engeström, Y., 1991, 'Developmental work research: Reconstructing expertise through expansive learning', in M. Nurminen \& G. Weir (eds.), Human jobs and computer interfaces, pp. 265-290, Elsevier, Amsterdam.

Engeström, Y., 1999, 'Innovative learning in work teams: Analyzing cycles of knowledge creation in practice', in Y. Engeström, R. Miettinen \& R.-L. Punamaki (eds.), Perspectives on activity theory, pp. 377-406, Cambridge University Press, New York.

Engeström, Y., 2001, 'Expansive learning at work: Toward an activity theoretical reconceptualization', Journal of Education and Work 14(1), 133-156. https://doi. org/10.1080/13639080020028747

Foot, K.A., 2014, 'Cultural-historical activity theory: Exploring a theory to inform practice and research', Journal of Human Behavior in the Social Environment 24(3), 329-347. https://doi.org/10.1080/10911359.2013.831011

Geertz, C., 1973, 'Thick description: Toward an interpretive theory of culture', in C. Geertz (ed.), The interpretation of cultures, pp. 310-321, Basic Books, New York.

Greenfield, D., 2010, “"When I hear Afrikaans in the classroom and never my language, I get rebellious": Linguistic apartheid in South African higher education', Language and Education 24(6), 517-534. https://doi.org/10.1080/09500782.2010.502969 
Hammerness, K., Darling-Hammond, L., Bransford, J., Berliner, D., Cochran-Smith, M.M., McDonald, M. et al., 2005, 'How teachers learn and develop', in in L. Darling-Hammond \& J. Bransford (eds.), Preparing teachers for a changing world: What
learn and be able to do, pp. 358-389, John Wiley \& Sons, Hoboken, NJ.

Henning, E. \& Gravett, S., 2011, 'Pedagogical craft and its science: Janus-faced in preservice teacher education', Education as Change 15(suppl 1), S21-S33. https:// doi.org/10.1080/16823206.2011.643617

Heugh, K., 2011, 'Theory and practice: Language education models in Africa: Research, design, decision-making and outcomes', in A. Ouane \& C. Glanz (eds.), Optimizing learning, education and publishing in Africa: The language factor, pp. 105-157, UIL/ADEA, Hamburg.

International Reading Association, 2003, Investment in teacher preparation in the United States. A position statement of the International Reading Association International Reading Association, Newark, DE.

Lesufi, P., 2015, Gauteng DoE to convert 124 Afrikaans schools to parallel medium, Politics Web, viewed 28 June 2015, from https://politicsweb.co.za/politics/ gauteng-doe-to-convert-124-afrikaans-schools-to-pa.

Nel, M. \& Theron, L., 2008, 'Critique of a language enrichment programme for Grade 4 ESL learners with limited English proficiency: A pilot study', South Africa Journa of Education 28(2), 203-219.

Ngcobo, S., 2013, 'Educator's attitudes towards the role of isizulu in education: Additive rather than exclusive', Southern African Linguistics and Applied Language Additive rather than exclusive', Southern African Linguistics and Applied Langu
Studies 31(2), 185-205. https://doi.org/10.2989/16073614.2013.815838
OECD, 2016, PISA 2018 draft analytical literacy frameworks, OECD Publishing, Paris.

Priestley, M., Biesta, G. \& Robinson, S., 2015, Teacher agency: An ecological approach, Bloomsbury Publishing, London.

Skogen, K. \& Krange, O., 2003, 'A wolf at the gate: The anti-carnivore alliance and the symbolic construction of community', Sociologia Ruralis 43(3), 309-325.

Spaull, N., 2013, 'Poverty and privilege: Primary school inequality in South Africa', International Journal of Education Development 33(5), 436-447.

Taylor, N. \& Mayet, A., 2015, 'A closer look at teacher education', JET Bulletin, pp. 2-6, February edn.

Van der Vyver, S., 2012, 'Methodology and theory in a rural ECD research project: Capturing Mogwase in "becoming", South African Journal of Childhood Education (SAJCE) 2(1), 140-158. https://doi.org/10.4102/sajce.v2i1.26

Vygotsky, L., 1978/1934, Mind in society. The development of higher psychological processes, eds. and transl. M. Cole, V. John Steiner, S. Scribner \& E. Souberman, Harvard University Press, Cambridge, MA.

Webb, V., 2010, 'Constructing an inclusive speech community from two mutually excluding ones: The third Afrikaans language movement', Tydskrif vir Letterkunde 47(1).

Zeichner, K., 2010, 'Rethinking the connections between campus courses and field experiences in college- and university-based teacher education', Journal of Teacher Education 61(1-2), 89-100. https://doi.org/10.1177/0022487109 347671 